The author deserves credit for his appendix, in which a series of simple physiological experiments are described, with a view to their repetition by the student.

\section{FRANCIS DARWIN.}

\section{OUR BOOK SHELF.}

Plant Organization: a Review of the Structure and Morphology of Plants by the written method. By R. Halsted Ward. (Boston, U.S.A. : Ginn and Co., I89o.) THIS is nothing more than a series of blank charts, intended for students to fill in with the details of plant descriptions. The charts are prefaced by a few pages of letterpress, wherein are contained some of the author's views on plant morphology, together with general hints and a summary of the terminology to be used. We cannot say that the author's attempt to simplify the technical terms ordinarily made use of in descriptive work is altogether a success. For instance, the words " shingled" and "straddling" for imbricate and equitant, will hardly recommend themselves to teachers on this side of the Atlantic; nor are plants either epiphytic or parasitic on rocks. As to the blank charts which constitute the feature of the book, it can only be said that, as such things go, they are entirely praiseworthy. But are charts of this kind really necessary? A child just beginning the subject may profitably make use of the very simple schedules devised by the late Prof. Henslow ; but by the time he has advanced so far as to be able to use these complicated and detailed ones, drawn up by Mr. Ward, we think he will do much better without being kept in leading-strings. The advantage gained by writing descriptions will be vastly enhanced if he be now permitted to think a little for himself.

$$
\text { F. W. O. }
$$

Geometrical Conics. Part I. The Parabola. By Rev. J. J. Milne, M.A., and R. F. Davis, M.A. (London: Macmillan and Co., 1890 .)

IN this work a departure is made from the general order of the propositions adopted by most geometrical writers "so as to bring the argument into closer agreement with that found in analytical text-books, in order that both methods may be studied side by side." Instead of a series of detached propositions, the authors have made a continuous treatise, and by this means have been able to deal with some of the more important points more fully than they otherwise could have done.

This part, which treats of problems and theorems relating only to the parabola, is thoroughly well done, and contains many problems fully worked out which are absent from other similar books.

Those reading the subject for the first time ought to have no difficulty in grasping the various propositions and theorems, and at the end numerous examples on them, with hints and solutions, are added.

Short Logarithms and other Tables. By W. Cawthorne Unwin, F.R.S. Fourth Edition. (London: E. and F. N. Spon and Co., I 890.)

THE short tables given in this book will be found to serve the purpose for which they were intended, which is to facilitate practical calculations and to solve arithmetical problems in a very complete way. The logarithmetic table is very short, but, if used properly, the error need not exceed one per thousand; logarithms of three-figure numbers to 999 , and of four-figure numbers to 2000 , are given.

Amongst the other tables are: anti-logarithms, natural and logarithmetic trigonometric functions, functions of numbers, product of numbers, table of weights and measures, and conversion tables for English and metric measures. The last-named table is inserted specially for NO. IOgI, VOL. 42 ] the use of engineers, as so many treatises on engineering are now being published in France and Germany in which the measures are given according to the metric system, and in consequence of which constants for the quick conversion of these measures are required.

W.

Elementary Algebra. By Charles Smith, M.A. (London: Macmillan and Co., I890.)

THIS is a second edition of this well-known book, and differs from the first in some important particulars. It has been thoroughly revised, and the early chapters have been simplified and remodelled. Chapters on logarithms and scales of notation form a useful and valuable addition, and there is a great increase in the number of the examples. For beginners this work should prove invaluable, and even more advanced students would do well to glance over its pages.

W.

\section{LETTERS TO THE EDITOR.}

[The Editor does not hold himself responsible for opinions expressed by his correspondents. Neither can he undertake to return, or to correspond with the writers of, rejected manuscripts intended for this or any other part of NATURE. No notice is taken of anonymous communications.]

\section{British Association Procedure.}

I SHOULD be sorry if Prof. Lodge or anyone else should suspect me of a desire to interfere with the opportunities which are afforded by meetings of the British Association for friendly intercourse between workers, and especially between the younger scientific men and their seniors, for I feel that those opportunities constitute one of the chief advantages of attending the meetings. But with the desire to avoid waste of time in merely journal business I should prefer that each Sectional Committee should be reduced to a small executive body to whom could be entrusted the task of arranging the programme for each day, and in a preliminary way other business, such as the selection of committees to carry out suggested new researches. The appointment of such Committees and the other business would be accomplished quickly enough at a meeting of the whole Section, and then opportunity would be given to all the members for expressing an opinion or offering suggestions. The plan at present adopted is neither one thing nor the other. The Sectional Committees are too large for the despatch of business, and yet may not include every desirable member of the Section. The demand for election to which I referred comes from a certain class of people whose single purpose is served when they get their names printed on the list.

I happen to have by me the journals of the Birmingham meeting, and the number of names on the Committees of the first three Sections I find as follows :--

$$
\begin{array}{rrrrrrrr}
\multicolumn{4}{c}{\text { Section A }} & & \text { B } & & \text { C } \\
\text { Vice-Presidents } & \ldots & 6 & \ldots & 9 & \ldots & 7 \\
\text { Secretaries } & \ldots & \ldots & 4 & \ldots & 5 & \ldots & 4 \\
\text { Committee } & \ldots & \ldots & 52 & \ldots & 5 \text { I } & \ldots & 93 \\
\text { Totals } & \ldots & \ldots & 62 & & 65 & & \text { IO4 }
\end{array}
$$

When numbers like this are reached why pretend to draw a line at all?

Birmingham, September 23. William A. Tiliden.

\section{The Exploration of Central Asia.}

The late notice in NATURE of August I4 (p. 378) with reference to the work of exploration now being carried out by the Russians around Kashgar, and that M. Grombchevsky, having received permission and funds to continue his work, was starting for Rudok, is not pleasant reading for Englishmen who know that part of the Himalayas. Rudok is a small place with a fort and Gonpa or monastery, and gives the name to the tract of country lying at the eastern end of the great Pangkong Lake, on the very confines of the territcry of the Kashmir State. In I 863 I carried the survey up to that extreme eastern limit, and succeeded by avoiding observation in getting within a very few 